\title{
Effects of leadership on the effective performance of Ethiopian banking industry
}

\author{
Debebe Alemu Kebede*; Kenenisa Lemi \\ College of Business and Economics, Jimma University, Ethiopia \\ *To whom correspondence should be addressed.Email: debealex2@gmail.com

\begin{tabular}{|l|l|l|l|l|}
\hline DOI: & Received: & Revised: & Accepted: & Published: \\
$10.22437 /$ ppd.v8i4.9418 & 30.05 .2020 & 16.08 .2020 & 19.08 .2020 & 07.11 .2020 \\
\hline
\end{tabular}

\begin{abstract}
The aim of the study was to examine the effect of leadership on organizational performance with specific reference to Commercial banks operate in Jimma Town. To achieve the objectives the study causal type of research and panel design was used to examine effect that leadership exert on the bank's performance. The primary data sources were leaders on different levels and their subordinate employees while, the secondary data sources were annual report of individual banks. Multifactor Leadership Questionnaire was adapted for collecting the data. The descriptive and inferential analyses was conducted to analyze the collected data. Subsequently, the Random Effect Model was used to investigate the extent of relationship between variables. The study results revealed that the existing leadership brings changes in working environment by inspiring and motivating employees for changes, creation, innovation, to go beyond from what they actually think they can; and reward employees and make recognition in exchange for the work they perform, giving close directions and guidance have positive and significant effect in promoting the performance of the bank. Hence, the leaders of banks should focus on playing a role model and stakeholders in the industry should consider taking banking in a non-traditional.
\end{abstract}

Keywords: Banks, Performance, Transactional leadership, Transformational leadership

JEL Classification: G21, L25, M21

\section{INTRODUCTION}

For the last half century the field of leadership has struggled to under-stand what exactly leadership is, under what contexts or situations it is effectively exercised, and how to explain leadership processes in addition to leader traits, skills and competencies (Bass, 1990; Yukl, 2006). Although no ultimate definition of leadership exists, however, leadership research spans a variety of approaches and has sometimes had mixed findings as one area of leadership that is agreed upon is that leadership does not affect a single person, but rather it affects many people (Dienesch \& Liden, 1986) \& so also the majority of definitions of leadership reflect some basic elements, including "group" "influence" and "goal" (Bryman, 1992).

In other words, the essence of leadership is not found in the leader per se, but in the relationship that exists between the leader and his or her subordinates and it is the process 
of influencing others towards achieving some kind of desired outcome. Leadership, as defined by Northouse (2004), is a process whereby an individual influence a group of individuals to achieve a common goal. Leadership style is the way in which that process is carried out. Performance is the accomplishment and execution of tasks. According to Albrecht (2011), performance is the extent to which an organization achieves a set of predefined targets that are unique to its mission. Leadership style is a key determinant of the success or failure of any organization. Thus, ensuring the effective leadership is becoming a critical issue for the success of modern business organization and the focus on it is increasing recently as the challenge of running business is enormous. So far, several theories had emerged and paved the way for the coming of modern leadership styles that can be understood in the organizational context.

Despite the fact that the impact of leaders seems intuitively appealing, most behavioural leadership studies look at performance or effective outcomes to extant theories of leadership which has been proposed over the past half-century and are exclusively on behaviour and interactions (i.e. doing) or traits, competencies or styles (i.e. having) (Daft, 2008). Leadership style is the way in which that process is carried out. Performance is the accomplishment and execution of tasks. According to Albrecht (2011), performance is the extent to which an organization achieves a set of pre-defined targets that are unique to its mission. Leadership style is a key determinant of the success or failure of any organization. Thus, ensuring the effective leadership is becoming a critical issue for the success of modern business organization and the focus on it is increasing recently as the challenge of running business is enormous. So far, several theories had emerged and paved the way for the coming of modern leadership styles that can be understood in the organizational context.

Transformational and transactional are the two recent leadership styles that researchers have been suggesting for organizational success in different circumstance. Compared to others, the financial sector in Sub Saharan Africa is lagging behind (Kefela, 2008). Ethiopia is no exception to it. The less infrastructure facilities (technology, service delivery, less capital) and ineffective management system have been the main reason among others that makes Ethiopian banking industry to remain closed for foreign investors and continue to operate in unique business environment even from its neighboring East African countries like Kenya, Tanzania, and Uganda. The least development of social and economy signifies the malfunctioning of banking sector in the country. However, Kefela (2008), points out that the loose in management system within individual banks is the cause for all problems in the banking sector.

In modern organizations such as banks, a hypercompetitive and hyperchanging business environment imposes a need for permanent improvement of quality of products, services, and business processes, as well as the need for conducting continuous training and development of their employees. Thus, for example, banking institutions pay special attention to the so-called "quality of service", which implies kindness, sensibility, and welldeveloped skills of verbal and non-verbal communication, referring to the general art of communication of banking offirs with bank clients (Tomašević-Lišanin, 1997).

Research in the leadership fild illustrates a positive correlation between the applied style of leadership, employee/followers job satisfaction (along with their performance) and the profiability of organizations (Odom \& Green, 2003; Harris, Harris, \& Eplion, 2007; Yahaya \& Ebrahim, 2016).

The banking industry is the most important financial institution in Ethiopia, dominating most of financial activities. Moreover, the sector is not well developed and less integrated with global financial market and the market is not competitive (ILO, 2009). 
Less infrastructure development: technology, service delivery, less capital, and ineffective management system are discernible features in Ethiopian banking sector. Banks in Ethiopia sticks to traditional ways of doing things. Engaging on daily routine work is the common duties of both managers and employees. Most of managers are spending their time on routine duties like attendance and dress code monitoring, writing related rules and regulations that urges the following of punishment for any deviation happened against the outlined rule. This high focuses on irregularities, mistakes, exceptions, and deviations are consuming much time of mangers and making them to be less effective on prediction about the future and relating the work at hand with the articulated vision of the bank. Moreover, wide gap is observed in understanding of the vision and the mission of the bank among the workers. There are only few managers that clearly communicate what the vision is and confident in attainment of it.

On the other hand, employees are complaining as their individualistic and communal need is not well considered and less room is given for their say. This discourages employees to feel belongingness to the bank which in turn leads to less productivity. Their voice is continued to be ignored and no room is being given for their say. They are not participating in the decision process that all policies and big decisions reveled to them after it is made at the top. There is visible bridge between managers and employees that no free discussion is possible and most employees are not comfortable to share what they think. These show the seriousness of leadership malfunctioning in Ethiopian banking industry. Ensuring the presence of effective leadership is one the critical strategies suggested by Bass \& Avoilo (1999) to increase the performance and remain in business.

The leadership style drives the ability of an organization performance, to successfully implement business strategies, to gain a competitive advantage and optimize human capital (Teshome, 2011). The dependency of organizational performance on the leadership effectiveness has been demonstrated by several studies (Teshome, 2011; Cole et al., 2009; Wang et al. 2011). Even though some studies support the superiority of transformational leadership style over transactional leadership style, the other claim the superiority of transactional leadership style over transformational leadership style for better organizational performance; some still suggests the combination of both leadership styles with various degrees according to the situation. In line with this, the study will be examining the effect of leadership on organizational performance in case of Commercial banks operate in Jimma Town.

\section{LITERATURE REVIEW}

According to Sadeghi (2012) the major components of transformational leadership style are Idealized influence, Inspirational Motivation, Intellectual Stimulation and Individual Consideration. While, Bass (1985) distinguishes two leadership factors within transactional leadership, namely contingent reward and management-by-exception.

\section{Idealized influence}

Idealized influence is one of the components of transformational leadership style that the leader's employee to get superior results. It is a component where being a role model of a leader can be perceived by followers so as it inspires them (Moss \& Ritossa, 2007). The followers can identify their role model easily and try to imitate as they admire, respect, and trust them (Bass et al., 2003). This is achieved by the fact that they share risks with their followers and, importantly, they are consistent, rather than arbitrary. Leaders with idealized characteristics are the role models that they walk first on the way they talk about (Avolio et al., 2004). Again, the transformational leader with an idealized 
influence are highly disciplined who do not use power for their own personal gain; they display high standards of moral and ethical conduct. The idealized influence also relates to charisma which, for long has been held as a mystical gift that people possess. It is true that there is more to being a leader than being a charismatic person.

\section{Inspirational motivation}

Inspirational Motivation is a component of transformational leadership style that describes the degree that the leader states attractive and encouraging vision to followers. Transformational leaders motivate and inspire those around them by providing meaning and challenge to their followers' work. They also focus strongly on team spirit. Followers are included in developing inspiring future visions and the leaders are effective communicators. The transformational leaders communicate their expectations clearly with their followers. They also display commitment to goals and the shared vision. These leaders talk optimistically about the future and what needs to be done to achieve the vision.

\section{Intellectual stimulation}

Intellectual stimulation is a component of the transformational leadership that refers to the degree in which the leaders stimulate their followers to be innovative and creative. Transformational leaders stimulate their followers to be innovative and creative by questioning assumptions, reframing problems, and approaching old situations in new ways. They encourage creativity through the use of reasoning and evidence rather than unsupported opinion to solve such problems (Avolio et al., 1991). The transformational leader encourages the development of a culture of continuous questioning and thus continuous learning.

\section{Individualized consideration}

Individualized Consideration is a component of the transformational leadership style that explains the degree in which the leader pays attention to the need of individual employee. Transformational leaders pay attention to the individual employee and his or her needs rather than treating all followers alike and having the same needs. Time is spent teaching and coaching others in an effort to develop their strengths and promote selfdevelopment, by acting as coaches and mentors. The transformational leaders make sure that the employee has sufficient help and the resources necessary to complete the tasks at hand. In line with the above literature it hypothesized that:

\section{H1: The components of Transformational leadership style have significant effect on effective performance of the banking industry in Ethiopia}

\section{Contingent reward}

It refers to situations in which the leader gives compensation to employees when they perform according to contract or expectation. The leader will assign or get agreement on what needs to be done. The leader then promises rewards, or actually rewards others, in exchange for satisfactorily carrying out the assignment. Bass \& Avolio (1994) contend that contingent reward has been found to be reasonably effective as a style of leadership. It is, however, not as effective as the transformational leadership factors, which will be discussed in the next section, in motivating others to achieve higher levels of development and performance.

\section{Management-by-exception}

It explains the degree in which a leader watches follower closely for mistakes or role violations (Northouse, 2004). Passive management-by- exceptions used by leaders who only interfere in the employees work if they do not meet the desired goals. The leader 
waits passively for deviances, mistakes, and errors to happen and then take corrective action (Judge \& Piccolo, 2004; Bass \& Avolio, 1994). This type of leader avoids describing agreements, explaining expectations and standards to be achieved by subordinates, but will intervene after particular problems become apparent (Sadeghi et al. 2012).

Active management-by-exception refers intervening in people's work when they are not putting forth the effort expected of them. Leaders will arrange actively to monitor deviances from standards, mistakes and errors in the follower's assignments and will take corrective action as necessary. Bass \& Avolio (1994) demonstrate that although management-by-exception is necessary in some situations, it is generally ineffective as it is a prescription for mediocrity. Managers who rely heavily on passive management-byexception, usually only attempt to sort problems out when they become chronic, which in many instances is too late. Those who employ active management-by-exception on a regular basis tend to focus too heavily on mistakes and in this way demotivate the workforce. In line with the above literature it hypothesized that:

H2: The components of Transactional leadership style have significant effect on effective performance of the banking industry in Ethiopia

\section{Effective performance}

Performance is a multidimensional construct and therefore multiple measures of performance should be used (Lumpkin \& Dess, 1996). Growth has been argued as an essential element to the attainment of sustainable competitive advantages and profitability (Markman \& Gartner, 2002) and it is hard to associate sustained growth without profitability. Evaluation of bank performance traditionally includes the four performance measures: ROA, efficiency ratio, net interest margin, and return on equity (Cole, 2009). Return on total assets (ROA) is known to measure the effectiveness of managerial performance and one of the most frequently used financial ratios by financial analysts. ROA measures the ability of bank management to generate income after all financial and non- financial costs and expenses for owners. Changes in ROA are usually the cause of the most important changes in banks' performance and need a more detailed analysis (Cole, 2009). Therefore, the measure of effective performance in this study is ROA.

\section{Conceptual framework}

\section{Independent Variables \\ Dependent}

Transformational Leadership Style (TRS)

- Idealized Influence (II)

- Inspirational Motivation (IM)

- Intellectual Stimulation (IS)

- Individualized Consideration (IC)

Transactional Leadership Style (TSL)

- Contingent Reward (CR)

- Management by Exception- Active (EMA)

- Management by Exception- Pasive (EMP)

Source: Self developed based on literature review

Figure 1. Conceptual framework 


\section{METHODS}

\section{Research design}

To achieve the objective of the study the causal type of research and panel design was employed. The causal research type uses to assess the nature of relationship and its extent between independent and the depended variables. On the other hand, the panel data gives the advantageous that either time series or cross sectional does not controllers individual heterogeneity, reduce co linearity variables and track trends in the data (Baltagi 2005). The research method employed in the study is quantitative, used to describe trends or tendency between variables.

\section{Target population and sampling design}

There are 8 commercial banks that are operating in the Jimma town. The target banks are those operating more than five consecutive years. Hence, five commercial banks in Jimma town was fulfil the criteria. The target population became the leaders (CEOs, department level managers, and the team leaders or division managers) and their subordinate staffs of the selected commercial banks. Census were applied since the number of banks and target population within the selected banks are few in number.

\section{Data type, sources and collection instruments}

For the purpose of the study both primary and secondary data was used. The primary data sources was collected from target population by using Multifactor Leadership Questionnaire (MLQ Form 5X) that is a validated form (instrument) that contains eight subscales and 40 items (Avolio \& Bass, 2004) will be adapted for collection of leadership styles representing questions. On the other hand, the secondary data source was the selected banks performance measurement, ROA directly from annual report of individual banks and from audit financial report of National Bank of Ethiopia (NBE). Participants were asked to rate the scale that consists 5 points, ranging from 0 to 4 , as how they ,"eecerceive that their leaders are the exhibiting or acting in accordance with the specific behavior explained in questions. The points are labeled as $0=$ not at all, $1=$ once in a while, 2 = sometimes, 3 = fairly often, 4 = frequently, if not always.

\section{Method of data analysis}

Both descriptive and inferential analyses was conducted by using STATA version 14 used to facilitate the analysis. The researcher employed Random Effect Model (LM) to investigate the extent of relationship between independent variables and dependent variables.

\section{Validity test}

The multifactor Leadership Questioner will be one of the most extensively used instrument by several researchers to assess individual and organizational success and to evaluate the leadership in different fields. Avolio \& Bass (2004) pointed out as the instrument was used extensively in field and laboratory research to study transformational, transactional, and passive/avoidant leadership style. Again, they stated as the instrument has been in use for over two decades evaluating the leadership effectiveness in military, government, education, religion, and other areas. The MLQ was adopted by Avolio et al. (2004) and Gupta \& Krishnan (2004) 'for determination of role of collective efficacy in the relations between transformational leadership and work outcomes" and "to assist in providing an understanding of transformational leadership behaviors shown by leaders vary depending on the follower's socialization method ${ }^{\text {ee }}$ respectively. 


\section{Reliability test}

The questions are requiring $10+2$ education to complete and timeframe of 15 minutes. This version of the MLQ has been updated to account for previous concerns and criticisms of the instrument (Cole 2009). Authors of this particular questionnaire have over 20 years of experience invalidating evidence for the MLQ and through that experience they have developed a strong foundation for what contributes to the success of such an instrument (Avolio \& Bass, 2004). The MLQ (5X-Short Form), which is a validated instrument that contains 40 items, was used for the research.

The value of Cronbach's Alpha (0.884) is greater than 0.5 that suggests that Categorical Data used is Reliable for Linear Regression Analysis. On the basis of Reliability test, now the Regression analysis may be made to investigate the effect of Leadership styles on the organizational Performance.

\section{RESULTS AND DISCUSSIONS}

This section presents the analysis, discussion and inferences made on the basis of the responses obtained. The research instrument used in the study was survey questionnaire. The study population comprised the commercial banks' leaders and subordinates. Data was collected from all selected commercial bank's leaders and subordinates of 135 which comprises $85 \%$ of target population.

\section{The descriptive statistics}

Table 1 presented the Multifactor Leadership Questionnaire assessment of leadership based on seven leadership behaviors and two leadership outcomes. Through the components of transformational leadership, five leadership behaviors, assess the leader's transformational dimensions. It describes leadership behaviors that inspire, motivate, stimulate and are considerate of others' higher potential. The range of transformational leadership profile of managers were Idealized Influence - Attributed 11.4, Inspirational Motivation (8.33), Intellectual Stimulation (8.54), and Individualized Consideration (13.55). They also considered their follower's opinions and communicating to followers that the vision is achievable.

Table 1. Leadership styles behavior

\begin{tabular}{lrrrrrrrrr}
\hline Items & II & IM & IS & IC & CR & EMA & EMP & TRS & TSL \\
\hline Mean & 11.4 & 8.33 & 8.54 & 13.55 & 5.42 & 2.51 & 3.42 & 41.82 & 11.35 \\
Std. & 1.42 & 1.66 & 1.45 & 3.44 & 2.91 & 1.51 & 2.13 & 7.97 & 6.55 \\
\hline
\end{tabular}

Source: Survey, 2019

Intellectual stimulation and Individualized Consideration behaviors of leaders are active one. Active transformational leadership is employed when the individual chooses leadership behavior designed to raise follower's consciousness about goals and values (Bass, 1996). Idealized influence behavior and inspirational motivation emphasize motivating followers to go beyond personal or individual interests for the good of the group (Burns, 1978). This is consistent with the findings of this study. More specifically, idealized influence is charismatic and seeks to inspire followers into action (Bass, 1996). The mean value of overall Transformational leadership behaviors of the managers is 41.82 and standard deviation is 7.97. It shows that they are also using Transformational style frequently. The leaders are monitoring and controlling outcomes at the mean time they are given the chance to follower's independent growth.

Further, transactional leadership describes Contingent Reward; Management- byException (Active) and Management- by- Exception (Passive). The mean values of these 
dimensions are 5.42, 2.51 and 3.42 respectively. The leaders are having considerable level of Contingent Reward behavior and Passive. The leaders are classifying role of followers and they also provide material and psychological reward contingent on the fulfillment of objective. They also helped to solve the problem when compliance has occurred. The leaders are occasionally involved with the followers work to correct them. Contingent reward, although transactional, seem to suggest a leadership behavior associated with motivating others to achieve higher level of development and performance.

Leader assigns or gets agreements on what need to be done, the leader set reward for the exchange of transaction like awards, medals, respect, team recognition (Bas 1996). Leaders are having both transformational and transactional behaviors, with the mean values of 41.82 and 11.35. The leaders are expected to show similar transformational and transactional leadership style. The present study result is consistent with others studies such as Bass (1985), and Avolio \& Bass (1991) whose finding was that the leaders exhibit both transformational and transactional behaviors that differentiate leadership style. The leader then relates differently to colleagues, followers and supervisors. These differences encompass different behavior that is likely to emerge in different circumstances.

Furthermore, as evident from the empirical data, the findings indicate that the managers of public sectors organizations exhibited both transformational and transactional behavior. These are compelling findings since the literature (Avolio, Bass \& Jung, 1999; Avolio \& Locke, 2002; Bass, Avolio, Jung \& Benson, 2003) indicates that the leaders exhibit transformational and transactional behaviors. These scholars examined the relationship of the transformational and transactional dimensions and found that leaders display the both leadership behaviour. Bass (1996) established that the leaders possessed both transformational and transactional leadership behaviours. Avolio \& Bass (2004) have shown that leaders have both transformational and transactional leadership behaviours, regardless of their ethnic culture.

\section{Effects of leadership on the effective performance of Ethiopian banking industry}

Table 2 and 3 presented as the Adjusted $\mathrm{R}$ square of transformational and transactional leadership behavior are 85.2 percent and 86.2 percent respectively which indicated as the the model explains the cause up to $85.5 \%$ and $86.1 \%$ and the model applied is reliable.

Table 2. Effects of transformational leadership on the effective performance of Ethiopian banking industry

\begin{tabular}{|c|c|c|c|c|c|}
\hline & \multicolumn{2}{|c|}{$\begin{array}{c}\text { Unstandardized } \\
\text { Coefficients }\end{array}$} & \multirow{2}{*}{$\begin{array}{c}\begin{array}{c}\text { Standardized } \\
\text { Coefficients }\end{array} \\
\text { Beta }\end{array}$} & \multirow[t]{2}{*}{$\mathrm{t}$} & \multirow[t]{2}{*}{ Sig. } \\
\hline & B & Std. Error & & & \\
\hline (Constant) & -17.955 & 4.658 & & -3.855 & .000 \\
\hline II & .832 & .711 & .950 & 3.171 & .004 \\
\hline IM & .740 & .801 & .790 & 3.109 & .003 \\
\hline IS & .643 & .849 & .409 & 4.040 & .000 \\
\hline IC & .730 & .651 & .826 & 3.761 & .000 \\
\hline$R$ Square $=.857$ & \multicolumn{3}{|c|}{ Adjusted $R$ Square $=.852$} & 94.035 & 000) \\
\hline
\end{tabular}


Table 3. Effects of transactional leadership on the effective performance of Ethiopian banking industry

\begin{tabular}{lccccc}
\hline & \multicolumn{2}{c}{$\begin{array}{c}\text { Unstandardized } \\
\text { Coefficients }\end{array}$} & $\begin{array}{c}\text { Standardized } \\
\text { Coefficients }\end{array}$ & $\mathrm{t}$ & \multirow{2}{*}{ Sig. } \\
\cline { 2 - 4 } & $\mathrm{B}$ & Std. Error & Beta & & \\
\hline (Constant) & 29.617 & .938 & & 31.562 & .000 \\
CR & 3.363 & .397 & .780 & 8.473 & .000 \\
EMP & 2.788 & .416 & .631 & 2.893 & .006 \\
EMA & 2.302 & .286 & .518 & 2.623 & .007 \\
\hline \multicolumn{1}{c}{$R$ S Square $=.864$} & \multicolumn{7}{c}{ Adjusted $R$ Square $=.861$} & $F=277.721$ (Sig. $=000)$ \\
\hline
\end{tabular}

The coefficients of determination $(\mathrm{R} 2=0.857$ and $\mathrm{R} 2=0.864)$ show the relative importance of the two leadership styles in explaining organizational performance in the Banks. These model explanatory powers show that transactional leadership style bears some relevance in explaining performance in banks than transformational leadership style. The square roots of these coefficients $(R=0.925$ and $R=0.930)$ indicate differing degrees of positive correlation between performance and leadership styles. That is, in the surveyed banks, performance is positively correlated with transactional leadership style than transformational leadership style. The result is also supported with the study of Bass \& Avolio (1994), Akar (2010), Sadeghi, et al. (2012); those concluded the transformational behavior of leadership brings changes and improvement in the working environment and stir ups the employees to performance.

The regression coefficients of both model summary indicated as the components are positive effect on effective performance of banking industry in Ethiopia. Therefore, both hypothesis is accepted. The study result is consistence with expectation which is the considered components of leadership behavior's have positive effect on performance. The result also supported with the findings of Chung-Wen Yang (2008) and Amegayibor (2018) who state the existence of significant positive relationship between transformational leadership style and banks performance. Additionally, the study findings also supported with study of Arham \& Muenjohn (2012) which stated as the existence of positive and strong relation between transactional leadership styles organizational performances.

Hence, it can be concluded as the reward in exchange for the extra effort, recognition of the work are common in Ethiopian banking sector; bonus, promotion, salary increment takes place when banks get profit that employee are committed and perform well to be rewarded. Therefore, contingent recognition/reward and management by exception rather than charisma, inspirational motivation and intellectual stimulation/individual consideration could be appropriate leadership behaviors and strategies to induce them to perform.

\section{CONCLUSIONS AND RECOMMENDATIONS}

\section{Conclusion}

The random effect regression was carried out to examine how and to what extent each type of leadership style relate to banks performance, which, is measured in terms, ROA. The result depicted that existence of positive relationship effective performance of the banking industry in Ethiopia have with the considered variables which are consistent with previous studies. Also, the existence of positive and strong relation of transactional leadership style on the ROA implies the reward and recognitions that leaders make for 
fellow subordinates up on accomplishment of the given task has strong effect on the performance. Finally, this study concludes that both transformational and transactional leadership styles have positive and significant effect on bank performance that exhibiting or not exhibiting of both transformational and transactional leadership behaviors leads, respectively, to an increase or decrease on banks performance in Ethiopia.

\section{Recommendations}

Based on the results of the study the bank leaders in Ethiopia are recommended to exhibit the combination of both transformational and transactional leadership behaviors according to the ongoing work environment circumstances. The leaders of banks should focus on playing a role model by taking first step of what they talk about and keep consistent in their action in way that getting trust and loyalty from employees and in instilling confidence, commitment and vision in employees. In this way leaders can get employee's work commitment or improvement in their performance by assuring the psychological attachment of employees to the organization. They should encourage participation in decision making, leave much room for the employees say and delegate and make to feel full responsible. On the other hand the leaders in the bank should give attention to close guidance and close follow up or supervision to the employees when the employee seem new for the work at the hand. The leader should also tell clearly what is expected from the employee and attached rewards and recognition for the achievement to induce the improvement of the performance of employee and then bank as a whole.

Stakeholders in the industry should consider taking banking in a non-traditional direction by placing more emphasis on understanding leadership style and its effects on improving results. The leadership style is learnable that the stakeholders of the bank should consider the need to present training to leaders on leadership styles as a means to increase performance results. The stake holders might also consider holding national conferences on innovative leadership models used to support the vision of the banking industry and seminars might be warranted to show financial leaders how to apply leadership models to everyday activities and develop strategies that might goes with contemporary banking environment.

In future research, it would be interesting to assess causal relationships by taking more cross sectional data in different time using longitudinal design (e.g. observations or 59 interviews) to determine if the findings tested are likely to be sustained. Further research should also involve a larger sample size from survey covering whole population of the banks in Ethiopia. Future studies can also benefit by including leadership styles and other variables such as organizational culture and other environmental factors in determining the banks performance.

\section{REFERENCES}

Arham, A. F., \& Muenjohn, N. (2012). Leadership and organizational performance in Malaysian SMEs: The mediating role of entrepreneurial orientation. Business and Information, 2012, 31-41.

Akar, A. (2010). Transformational and transactional leadership characteristics of intercollagiate athletes and non-athletes. (Doctoral dissertation). Middle East Technical University, Turkey.

Albrecht, S. L., \& Andreetta, M. (2011). The influence of empowering leadership, empowerment and engagement on affective commitment and turnover intentions in community health service workers. Leadership in health services, 24 (3), 228 - 237

Amegayibor, G.K. (2018). Leadership styles and performance of employees at Ameen 
Sangari Company Limited, Cape Coast (Doctoral dissertation), University of Cape Coast.

Avolio, B.J., Waldman, D.A., \& Yammarino, F.J. (1991). Leading in the 1990s: the Four I's of Transformational Leadership. Journal of European Industrial, 15 (4)

Avolio, B.J., Luthans, F., \& Walumbwa, F.O. (2004). Authentic leadership: Theory building for veritable sustained performance. Working Paper, Gallup Leadership Institute, University of Nebraska, Lincoln.

Avolio, B. J., \& Zhu, W., Koh, W., \& Bhatia, P. (2004). Transformational Leadership and Organizational Commitment: Mediating Role of Psychological Empowerment and Moderating Role of Structural Distance. Journal of Organizational Behavior: The International Journal of Industrial, Occupational and Organizational Psychology and Behavior, 25(8), 951-968.

Baltagi, B.H., (2005). Econometric Analysis of Panel Data. West Sussex: John Wiley \& Sons Publish..

Bass, B. M. (1985). Leadership and Performance. New York: Free Press

Bass, B. M. (1990). From transactional to transformational leadership: Learning to share the vision. Organizational dynamics, 18(3), 19-31.

Bass, B. M., \& Avolio, B.J. (1994). Improving organizational Effectiveness through Transformational Leadership. Sage.

Bass, B.M., \& Avolio, B.J. (1996). Multifactor leadership questionnaire. European Journal of Psychological Assessment.

Bass, B.M., Avolio, B. J., Jung, D.I., \& Berson, Y. (2003).Predicting Unit Performance by Assessing Transformational and Transactional Leadership. Journal of Applied Psychology, 88, 207-218.

Bernard M. Bass. Avolio J.B. (1999). Transformational Leadership and Organizational Culture. Public administration quarterly, 112-121.

Bass, B. M., B. J. Avolio, D. I. Jung, and Y. Berson. (2004). Prediction Unit Performance by Assessing Transformational and Transactional Leadership. .Journal of Applied Psychology 88 (2): 207-18.

Bryman, A. (1992). Charisma and leadership in organizations. Sage Pubs.

Chung-Wen Yang (2008).The Relationships among Leadership Styles, Entrepreneurial orientation, and Business Performance. Managing Global Transitions, 6(3), 257.

Creswell John (3rd). (2009). Research Design" Qualitative, Quantitative, and Mixed Methods Approaches. SAGE publications.inc.

Cole, M. S., Bruch, H., \& Shamir, B. (2009). Social distance as a moderator of the effects of transformational leadership: Both neutralizer and enhancer. Human Relations, 62(11), 1697-1733.

Dienesch, R. M., \& Liden, R. C. (1986). Leader-member exchange model of leadership: A critique and further development. Academy of management review, 11(3), 618634.

Daft, R. L. (2008). The leadership experience 4th ed. Thomson South-Western, 20-21.

Gupta, V., \& Krishnan, V. R. (2004). Impact of socialization on transformational leadership: Role of leader member exchange. South Asian Journal of Management, 11(3), 7-20.

Hair, J F, Black, W C, Babin, B J, Anderson, R E, \& Tatham, R L (6thedn). (2006). Multivariate Data Analysis. New Jersey: Pearson Education.

Harris, K. J., Harris, R. B., \& Eplion, D. M. (2007). Personality, Leader-Member Exchanges, and Work Outcomes. Journal of Behavioral \& Applied Management, 
$8(2)$.

Judge, T.A. \& Piccolo, R.F. (2004). Transformational \& Transactional Leadership: A Meta-analytic Test of their Relative Validity. Journal of Applied Psychology, 89(5): 755-768.

Kefela, G.T. (2010). Understanding organizational culture and leadership-enhance efficiency and productivity. PM World Today, 12(1), 1-14.

Lišanin, T. (1997). Bank Marketing. Informator Zagreb.

Lumpkin, G. T., \& Dess, G.G. (1996). Clarifying the entrepreneurial orientation construct and linking it to performance. Academy of management Review, 21(1), 135-172.

Markman, G.D., \& Gartner, W.B. (2002). Is extraordinary growth profitable? A study of Inc. 500 high-growth companies. Entrepreneurship theory and practice, 27(1), 6575.

Moss \& Ritossa, D.A., \& Ritossa, D.A. (2007). The impact of goal orientation on the association between leadership style and follower performance, creativity and work attitudes. Leadership \& Organization Development Journal, 3(4), 433-456.

Odom, L., \& Green, M.T. (2003). Law and the ethics of transformational leadership. Leadership \& Organization Development Journal. 24(2), 62-69.

Sadeghi, A., \& Pihie, Z.A.L. (2012). Transformational leadership and its predictive effects on leadership effectiveness. International Journal of Business and Social Science, 3(7), 186-197

Teshome, T. (2013). The relationship between leadership styles and employee commitment in private higher education institutions at Addis Ababa City. Proceedings of the 11th International Conference on Private Higher Education in Africa

Wang, H., Tsui, A.S., \& Xin, K.R. (2011). CEO leadership behaviors, organizational performance, and employees' attitudes. The leadership quarterly, 22(1), 92-105.

Yahaya, R., \& Ebrahim, F. (2016). Leadership styles and organizational commitment: literature review. Journal of Management Development, 35(2), 190-216.

Yukl, G., \& Chavez, C. (2002). Influence tactics and leader effectiveness. Leadership, $1(1), 139-165$.

Yukl, G. (2009). Leading organizational learning: Reflections on theory and research. The leadership quarterly, 20(1), 49-53. 